\title{
Laser speckle flowgraphy findings in focal scleral nodule
}

\author{
Yui Yamashita $^{1} \cdot$ Michiyuki Saito $^{1} \cdot$ Kiriko Hirooka $^{1} \cdot$ Susumu Ishida ${ }^{1}$
}

Received: 22 June 2021 / Revised: 7 August 2021 / Accepted: 13 August 2021 / Published online: 8 September 2021

(c) The Author(s) 2021

\section{Key messages}

- Fung et al. renamed solitary idiopathic choroiditis to focal scleral nodule (FSN) in 2020.

- In 2 cases of FSN, reduction in blood flow on laser speckle flowgraphy was noted only in the area of involvement on clinical exam.

- Since FSN did not show a diffuse decrease in choroidal blood flow, which was the pattern of choroiditis, focal compression by scleral nodule but not choroiditis may be the primary condition of FSN.

\section{Dear Editor.}

Focal scleral nodule (FSN), renamed by Fung et al. in 2020 [1], is characterized by the partial elevation of the sclera and a solitary yellowish-white spot with clear boundaries. In the FSN lesion, the choroidal circulation may be locally impaired given previously reported hypofluorescence on indocyanine green angiography (ICGA) and nonperfusion of choriocapillaris on optical coherence tomography angiography [1]. To date, surveying macular choroidal blood flow using laser speckle flowgraphy (LSFG) has played an important role in elucidating the pathophysiology of various fundus diseases [2-8]; however, the LSFG findings of FSN has not been reported so far. Here, we report the LSFG findings in 2 FSN cases.

We would like to describe 2 cases. Our first case was a 56-year-old woman who was found to have an abnormality in her right fundus. Her medical and family history was unremarkable. The patient's best-corrected visual acuity (BCVA) was 20/20 OD. Funduscopic examination revealed an orange lesion of less than two-disc diameter on the inferonasal site of the macula (Fig. 1a).
Fluorescein angiography (FA) showed scattered hypofluorescence and surrounding hyperfluorescence (Fig. 1c) in the early phase followed by granular enhancement (Fig. 1d). ICGA showed hypofluorescence in the early phase (Fig. 1e) and surrounding slight hyperfluorescence in the late phase (Fig. 1f). On enhanced depth imaging optical coherence tomography (EDI-OCT), the sclera was elevated with the overlying choroid thinned to $20 \mu \mathrm{m}$ (Fig. 1g), whereas the central choroidal thickness was $144 \mu \mathrm{m}$. B-mode echography showed no acoustic shadow (Fig. 1h). Contrast-enhanced MRI of the head and orbit (Fig. 1i), gallium scintigraphy, and blood tests showed no abnormal systemic or ocular findings. The patient was diagnosed with FSN and followed up without treatment. Five years later, the yellowish-white lesion and surrounding orange halo became funduscopically more evident than at the first visit (Fig. 1b).

The LSFG color map of mean blur rate (MBR) showed localized cooler color at the lesion (white arrowheads, MBR = 4.6) than at the macula (black arrowheads, MBR =7.7), indicating blood flow was disrupted in the FSN site (Fig. 1j).

\footnotetext{
Michiyuki Saito

s.michiyuki@med.hokudai.ac.jp

1 Department of Ophthalmology, Faculty of Medicine and Graduate School of Medicine, Hokkaido University, N-15, W-7, Kita-ku, Sapporo 060-8638, Japan
} 


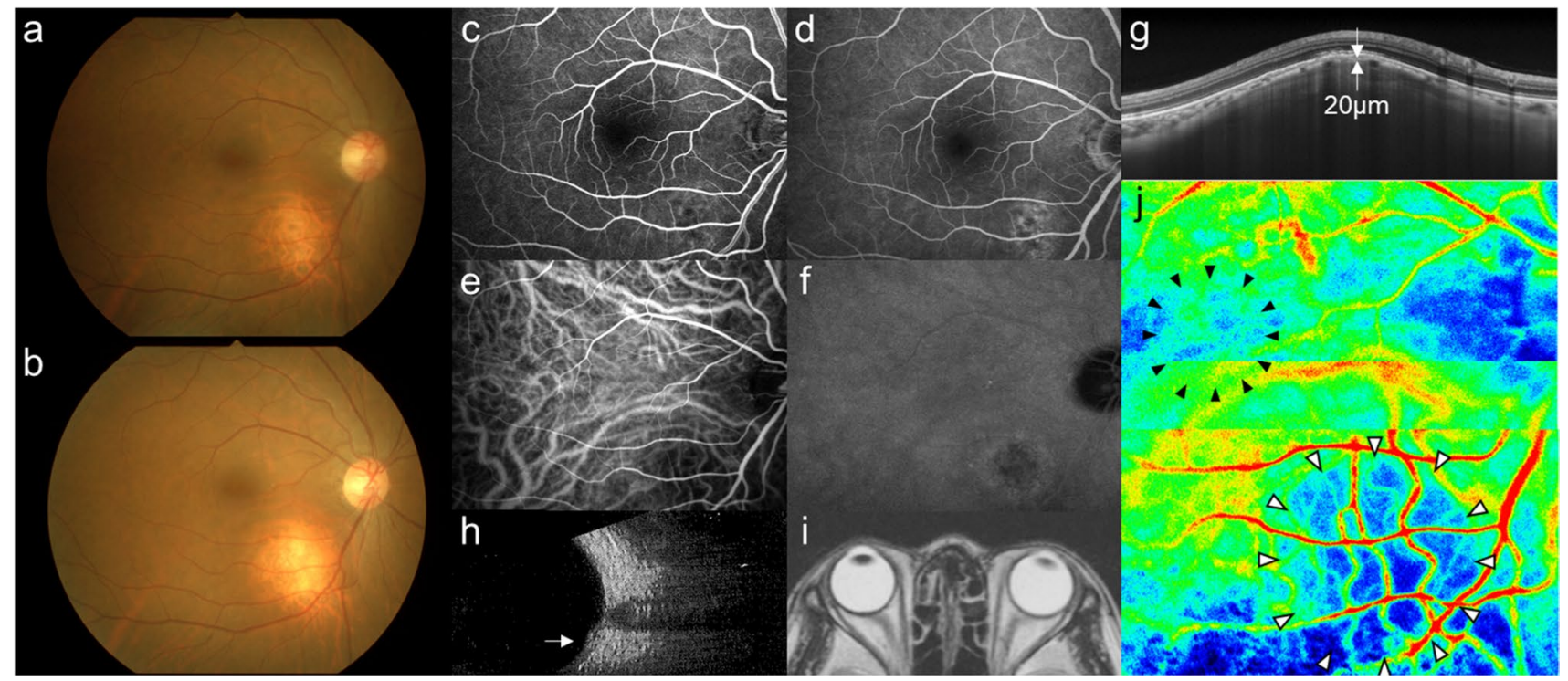

Fig. 1 Images of the right eye in a patient (Case 1) with focal scleral nodule (FSN). a The fundus photograph at the initial visit showing an orange lesion with well-defined choroidal vessels less than the twodisc diameter at the inferonasal site of the macula. b The FSN lesion was yellowish-white, and the surrounding orange halo became evident 5 years later. c Early-phase fluorescein angiography (FA) shows scattered hypofluorescence and surrounding hyperfluorescence. $\mathbf{d}$ The hyperfluorescence turned to granular enhancement in the late phase of FA. e Early-phase indocyanine green angiography showing hypofluorescence at the lesion. $\mathbf{f}$ The hypofluorescence persisted with

Our second case was a 56-year-old woman who was referred to our clinic because of a yellowish-white lesion in her left macula. Past medical and family history was unremarkable. BCVA was 20/16 OS. The fundus and other findings were similar to those in Case 1 (Fig. 2a-i), but the elevation was closer to the macula and steeper. Late-phase FA showed hyperfluorescence across the fovea, indicating retinal pigment epithelial damage (Fig. 2d).

On LSFG, the lesion showed a cooler color (Fig. $2 \mathrm{j}$ white arrowheads, MBR =3.3) than the macula (black arrowheads, $M B R=10.2$ ), indicating blood flow reduction in the FSN site. Five years later, the lesion became more apparent than at the first visit (Fig. 2b).

Since the yellowish-white lesion in this disease was once considered an inflammatory disease of the a new surrounding hyperfluorescence in the late phase. g Enhanced depth imaging optical coherence tomography showing the elevation of the sclera, with the overlying choroid thinned to $20 \mu \mathrm{m}$. h B-mode echography showing an elevated lesion (white arrow), but without acoustic shadow suggestive of calcification. i Contrast-enhanced MRI of the orbit shows no abnormal findings, including orbital tumors. $\mathbf{j}$ The laser speckle flowgraphy color map 1 year after the initial visit showing localized cooler color (white arrowheads) corresponding to the FSN lesion, indicating blood flow impairment

choroid, Hong et al. named it unifocal helicoid choroiditis in 1997 [9], and Shields et al. solitary idiopathic choroiditis in 2002 [10]. However, recent EDI-OCT findings prompted Fung et al. to rename these lesions to FSN, reporting that these lesions originate from the sclera and not the choroid [1]. In both cases of this report, the cooler LSFG color showed a focal reduction in blood flow. It is noteworthy that the LSFG findings were strictly localized in the lesion. Conversely, in inflammatory diseases such as punctate inner choroidopathy, whose primary condition is choroiditis, LSFG shows reductions in blood flow beyond the visible area of involvement on clinical exam [7], whereas in FSN, reduction in blood flow on LSFG is noted only in the area of involvement on clinical exam. The localized blood flow reduction in LSFG is a finding supporting the pathophysiology of FSN, a primary scleral 


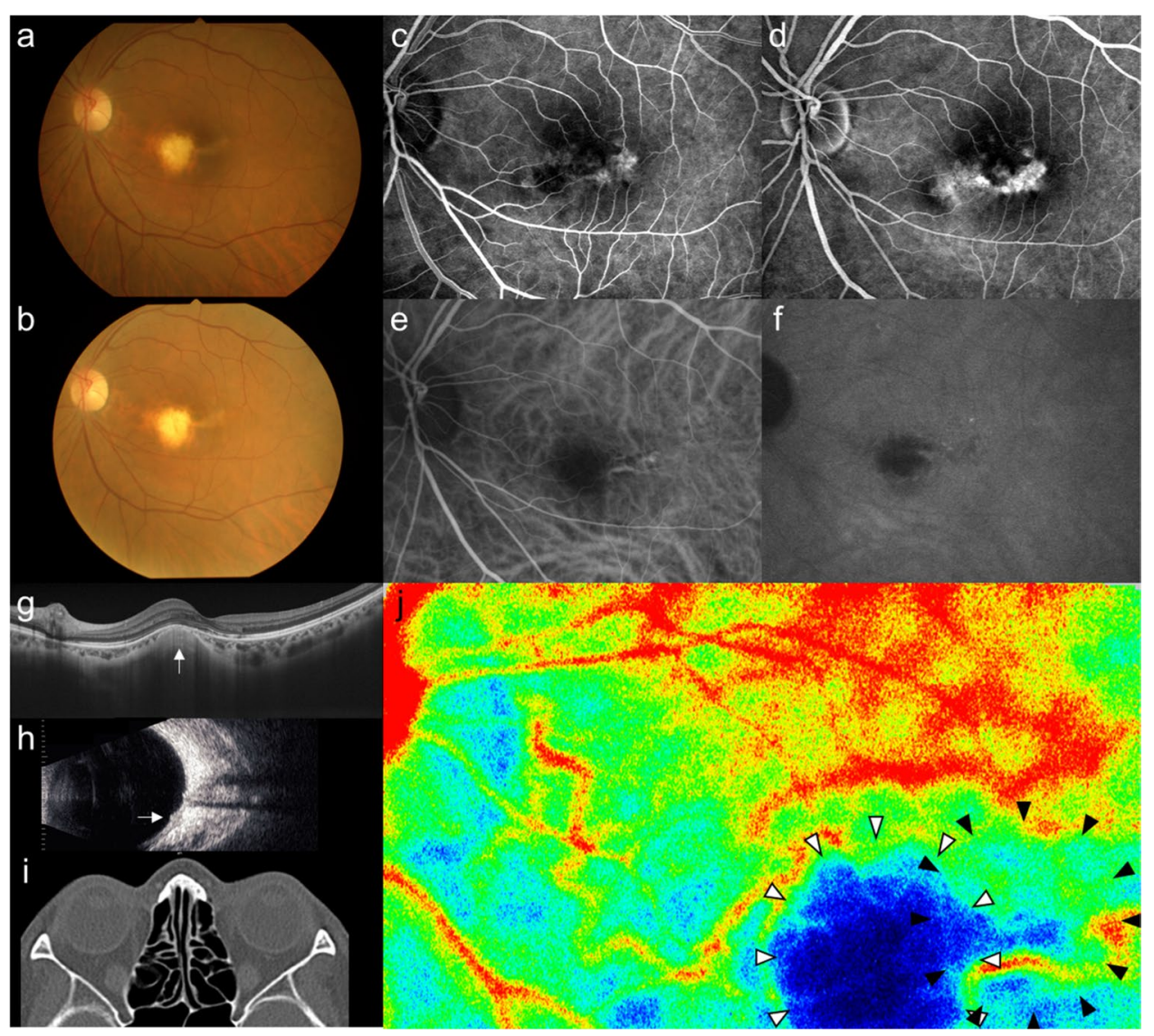

Fig. 2 Images of the left eye in a patient (Case 2) with focal scleral nodule (FSN). a The fundus photograph at the initial visit showing a whitish-yellow lesion of about one-disc diameter with an orange boundary neighboring the fovea. b The lesion and surrounding orange halo became more evident in the fundus photograph 5 years later. c Early-phase fluorescein angiography (FA) showing window defects corresponding to retinal pigment epithelium atrophy around the whitish-yellow lesion. d The hyperfluorescence was enhanced in the late phase of FA. e Early-phase indocyanine green angiogra-

elevation, and the resultant decrease in choroidal blood flow due to mechanical compression of the choroid.

Author contribution Conception and design, YY, MS, SI. Acquisition of data, YY, KH. Analysis and interpretation of the data, YY, KH. Drafting the manuscript, YY, MS, SI. Critical revision for intellectual content, YY, MS, SI.

Data availability Not applicable. phy showing low fluorescence at the lesion. $\mathbf{f}$ The hypofluorescence lesion persisted in the late phase. g Enhanced depth imaging optical coherence tomography showing the elevation of the sclera (white arrow), with the choroid compressed compared to the other parts of the choroid. h B-mode echography showing an elevated lesion (white arrow) with no acoustic shadow. i Contrast CT of the orbit showing no abnormal findings. $\mathbf{j}$ The laser speckle flowgraphy color map 3 months after the initial visit showing apparent solitary cooler color (white arrowheads) corresponding to the lesion

Code availability Not applicable.

\section{Declarations}

Ethics approval Not applicable.

Consent to participate Obtained patients' consent.

Consent for publication Not applicable. 
Conflict of interest Susumu Ishida; Alpha Communication Co., Ltd., White Medical Co., Ltd., Bloom Technology Corporation, AbbVie GK., Wakamoto Pharmaceutical Co., Ltd., AMO Japan Co., Ltd., Otsuka Pharmaceutical Co., Ltd., Senju Pharmaceutical Co., Ltd., Seed Co., Ltd., Japan Archon Co., Ltd., Bayer Yakuhin, Ltd, Santen Pharmaceutical Co., Ltd., Nidek Co., Ltd., and Bonak Co., Ltd.

Open Access This article is licensed under a Creative Commons Attribution 4.0 International License, which permits use, sharing, adaptation, distribution and reproduction in any medium or format, as long as you give appropriate credit to the original author(s) and the source, provide a link to the Creative Commons licence, and indicate if changes were made. The images or other third party material in this article are included in the article's Creative Commons licence, unless indicated otherwise in a credit line to the material. If material is not included in the article's Creative Commons licence and your intended use is not permitted by statutory regulation or exceeds the permitted use, you will need to obtain permission directly from the copyright holder. To view a copy of this licence, visit http://creativecommons.org/licenses/by/4.0/.

\section{References}

1. Fung AT, Waldstein SM, Gal-Or O, Pellegrini M, Preziosa C, Shields JA, Welch RJ, Dolz-Marco R, Sarraf D, Nagiel A, Lalane R, Jung JJ, Ghazi NG, Ramtohul P, Arnold JJ, Sakurada Y, Choudhry N, Balaratnasingam C, Freund KB, Shields CL (2020) Focal scleral nodule. Ophthalmology 127:1567-1577. https://doi.org/10.1016/j.ophtha.2020.04.018

2. Kataoka K, Kase S, Noda K, Ishida S (2020) Laser speckle flowgraphy findings in a patient with choroidal macrovessel. Ophthalmology Retina 4:1123-1124. https://doi.org/10.1016/j. oret.2020.06.018

3. Saito M, Noda K, Saito W, Hirooka K, Hashimoto Y, Ishida S (2020) Increased choroidal blood flow and choroidal thickness in patients with hypertensive chorioretinopathy. Graefes Arch Clin Exp Ophthalmol 258:233-240. https://doi.org/10.1007/ s00417-019-04511-y
4. Fukutsu K, Namba K, Iwata D, Mizuuchi K, Kase S, Suzuki K, Shimizu H, Shibata Y, Yamawaki F, Onozawa M, Ishida S (2020) Pseudo-inflammatory manifestations of choroidal lymphoma resembling Vogt-Koyanagi-Harada disease: case report based on multimodal imaging. BMC Ophthalmol 20:94. https://doi.org/10.1186/s12886-020-01353-9

5. Hirooka K, Saito W, Saito M, Hashimoto Y, Mori S, Noda K, Ishida S (2016) Increased choroidal blood flow velocity with regression of acute posterior multifocal placoid pigment epitheliopathy. Jpn J Ophthalmol 60:172-178. https://doi.org/ 10.1007/s10384-016-0440-6

6. Saito M, Saito W, Hirooka K, Hashimoto Y, Mori S, Noda $\mathrm{K}$, Ishida S (2015) Pulse waveform changes in macular choroidal hemodynamics with regression of acute central serous chorioretinopathy. Invest Ophthalmol Vis Sci 56:6515-6522. https://doi.org/10.1167/iovs.15-17246

7. Hirooka K, Saito W, Hashimoto Y, Saito M, Ishida S (2014) Increased macular choroidal blood flow velocity and decreased choroidal thickness with regression of punctate inner choroidopathy. BMC Ophthalmol 14:73. https://doi.org/ 10.1186/1471-2415-14-73

8. Saito M, Saito W, Hashimoto Y, Yoshizawa C, Fujiya A, Noda K, Ishida S (2013) Macular choroidal blood flow velocity decreases with regression of acute central serous chorioretinopathy. Br J Ophthalmol 97:775-780. https://doi.org/10.1136/ bjophthalmol-2012-302349

9. Hong PH, Jampol LM, Dodwell DG, Hrisomalos NF, Lyon AT (1997) Unifocal helioid choroiditis. Arch Ophthalmol 115:1007-1013. https://doi.org/10.1001/archopht.1997.01100 160177006

10. Shields JA (2002) Solitary idiopathic choroiditis. Arch Ophthalmol 120:311. https://doi.org/10.1001/archopht.120.3.311

Publisher's note Springer Nature remains neutral with regard to jurisdictional claims in published maps and institutional affiliations. 